\title{
Convergence Theorem of Hybrid Iterative Algorithm for Equilibrium Problems and Fixed Point Problems of Finite Families of Uniformly Asymptotically Nonexpansive Semigroups
}

\author{
Hongbo Liu, Yi Li* \\ School of Science, Southwest University of Science and Technology, Mianyang, China \\ Email: ${ }^{*}$ liyi@swust.edu.cn
}

Received 11 April 2014; revised 11 May 2014; accepted 18 May 2014

Copyright (C) 2014 by authors and Scientific Research Publishing Inc.

This work is licensed under the Creative Commons Attribution International License (CC BY).

http://creativecommons.org/licenses/by/4.0/

(c) (i) Open Access

\section{Abstract}

Throughout this paper, we introduce a new hybrid iterative algorithm for finding a common element of the set of common fixed points of a finite family of uniformly asymptotically nonexpansive semigroups and the set of solutions of an equilibrium problem in the framework of Hilbert spaces. We then prove the strong convergence theorem with respect to the proposed iterative algorithm. Our results in this paper extend and improve some recent known results.

\section{Keywords}

Hybrid Iterative Algorithm, Uniformly Asymptotically Nonexpansive Semigroups, Equilibrium Problem, Common Fixed Point

\section{Introduction}

Recall the following equilibrium problem. Let $C$ be a closed convex subset of a real Hilbert space $H$ with inner produce $\langle.,$.$\rangle and norm \|$.$\| . Let \phi: C \times C \rightarrow \mathbb{R}$ be a bifunction, where $\mathbb{R}$ is the set of real numbers. The equilibrium problem for $\phi$ is to to find $x \in C$ such that

$$
\phi(x, y) \geq 0, \quad \forall y \in C,
$$

the set of solutions is denoted by $E P(\phi)$.

${ }^{*}$ Corresponding author.

How to cite this paper: Liu, H.B. and Li, Y. (2014) Convergence Theorem of Hybrid Iterative Algorithm for Equilibrium Problems and Fixed Point Problems of Finite Families of Uniformly Asymptotically Nonexpansive Semigroups. Advances in Pure Mathematics, 4, 244-252. http://dx.doi.org/10.4236/apm.2014.46033 
A mapping $T$ of a normed space $H$ into itself is said to be nonexpansive if $\|T x-T y\| \leq\|x-y\|$ for each $x, y \in H$. We denote by $F(T)$ the set of fixed point of $T$. Given a mapping $T: C \rightarrow H$, let $\phi(x, y)=\langle T x, y-x\rangle$ for all $y \in C$. Then $x \in E P(\phi)$ if and only if $\langle T x, y-x\rangle \geq 0$ for all $y \in C$, i.e., $x$ is a solution of the variational inequality, there are several other problems, for example, the complementarity problem, minimax problems, the Nash equilibrium problem in noncooperative games, fixed point problem and optimization problem, which can also be written in the form of an EP. In other words, the EP is an unifying model for several problems arising in physics, engineering, science, optimization, economics, etc. In the last two decades, many papers have appeared in the literature on the existence of solutions of EP; see, for example ([1]-[3]) and references therein.

Iterative methods for finding fixed points of nonexpansivemappings are an important topic in the theory of nonexpansive mappings and have wide applications in a number of applied areas, such as the convex feasibility problem (see [4]-[7]), the split feasibility problem (see [8]-[10]) and image recovery and signal processing (see [6]).

In 1953, Mann [11] introduced the following iterative process to approximate a fixed point of a nonexpansive single valued mapping $T$ in a Hilbert space $H$ :

$$
x_{n+1}=\alpha_{n} x_{n}+\left(1-\alpha_{n}\right) T x_{n}, \quad \forall n \geq 1,
$$

where the initial point $x_{0}$ is taken in $C$ arbitrarily and $\alpha_{n}$ is a sequence in $[0,1]$. However, we note that Mann's iteration process has only weak convergence. To obtain strong converges for Mann iteration, Nakajo and Takahashi [12] and Takahashi et al. [13] introduce some hybrid iterative process. Motivated by Suzuki's result [14] and Nakajo-Takahashi's results [12].

On the other hand, Tada and Takahashi [15] introduce a new iterative method for finding a common element of the set of solutions of an equilibrium problem and the set of fixed points of a nonexpansive mapping $T$ in a Hilbert space $H$.

A family $\mathbb{T}:=\{T(s): s \geq 0\}$ of mappings on a closed convex subset $C$ of a Hibert space $H$ is called a nonexpansive semigroup if it satisfies the following conditions:

1) $T(0) x=x$ for all $x \in C$;

2) $T(s+t)=T(s) T(t)$ for all $s, t \geq 0$;

3) $\|T(s) x-T(s) y\| \leq\|x-y\|$ for all $x, y \in C$ and $s \geq 0$,

4) for all $x \in C, s \rightarrow T(s) x$ is continuous.

Takahashi and Chen [16] proved a strong convergence theorem for nonexpansive semigroups in Hilbert spaces by hybrid method in themathematical programming. Recently Saejung [17] improved the result in [16].

Takahashi's result gives us new idea that a finite family of uniformly asymptotically nonexpansive semigroups is introduced.

Definition 1.1 A family $\mathbb{T}:=\{T(s): s \geq 0\}$ of mappings on a closed convex subset $C$ of a Hibert space $H$ is called an uniformly asymptotically nonexpansive semigroup with sequence $k_{n}\left(k_{n} \geq 1\right.$ and $\left.\lim _{n \rightarrow \infty} k_{n}=1\right)$ if it satisfies the following conditions:

1) $T(0) x=x$ for all $x \in C$;

2) $T(s+t)=T(s) T(t)=T(t) T(s)$ for all $s, t \geq 0$;

3) $\left\|T^{n}(s) x-T^{n}(s) y\right\| \leq k_{n}\|x-y\|$ for all $x, y \in C, \quad s \geq 0, n \geq 1$

4) for all $x \in C, s \rightarrow T(s) x$ is continuous.

In this paper, we introduce a new hybrid iterative process for finding a common element of the set of common fixed points of a finite family of uniformly asymptotically nonexpansive semigroups and the set of solutions of an equilibrium problem in the framework of Hilbert spaces. Then we prove some strong convergence theorems of the proposed iterative process. Our results generalize results of Tada and Takahashi [15], Takahashi et al. [13], He and Chen [16] and Saejung [17].

\section{Preliminaries}

Throughout the paper, we denote weak convergence of $\left\{x_{n}\right\}$ by $x_{n} \rightarrow x$, and strong convergence by $x_{n} \rightarrow x$. Let $C$ be a closed convex subset of $H$, we use $\mathbb{T}$ to denote the common fixed points set of the semigroup $\mathbb{T}:=\{T(s): s \geq 0\}$. i.e., $F(\mathbb{T})=\{x \in C: T(s) x=x, \forall s \geq 0\}$.

Next, We present an example of an uniformly asymptotically nonexpansive semigroup. 
Example 2.1 As an example, we consider the nonempty closed convex subset $C=[$, $+\infty)$ of a Hilbert space $\mathbb{R}$. define $T(s) x=\exp (-s) x$. Observe that $T(s)$ is an uniformly asymptotically nonexpansive semigroup.

For every point $\in H$, there exists a unique nearest point in $C$, denoted by $P_{C} x$ such that

$$
\left\|x-P_{C} x\right\| \leq\|x-y\|, \quad \forall y \in C,
$$

that is, $P_{C} x=\inf _{y \in C}\|x-y\| . P_{C}$ is called the metric projection of $H$ onto $C$. It is well known that $P_{C}$ is a nonexpansive mapping. It is also known that $H$ satisfies Opial's condition, i.e., for any sequence $\left\{x_{n}\right\}$ with $x_{n} \rightarrow x$, following the inequality holds:

$$
\liminf _{n \rightarrow \infty}\left\|x_{n}-x\right\|<\liminf _{n \rightarrow \infty}\left\|x_{n}-y\right\|, \quad \forall y \in H, y \neq x .
$$

To prove our result, we recall the following Lemma.

Lemma 2.1 (see [18]). Let $C$ be a closed convex subset of $H$. Given $x \in H$ and a point $z \in C$. Then $z=P_{C} x$ if and only if $\langle x-z, y-z\rangle \leq 0$ for all $y \in C$.

Lemma 2.2 (see [12]). Let $C$ be a closed convex subset of $H$. Then for all $x \in H$ and $y \in C$ we have

$$
\left\|y-P_{C}\right\|^{2}+\left\|x-P_{C}\right\|^{2} \leq\|x-y\|^{2} .
$$

Lemma 2.3 (see [18]). Let $H$ be a real Hilbert space, there hold the following identities:

1) $\|t x+(1-t) y\|=t\|x\|^{2}+(1-t)\|y\|^{2}-t(1-t)\|x-y\|$, for all $t \in[0,1]$ and $x, y \in H$.

2) $\|x-y\|^{2}=\|x\|^{2}-\|y\|^{2}-2\langle x-y, y\rangle$, for all $x, y \in H$.

Lemma 2.4 (see [19]) Let $H$ be a real Hilbert space. For $i, j=1,2, \cdots, N$,

$$
\left\|\sum_{m=1}^{N} a_{m}\right\|^{2}=\sum_{m=1}^{N} a_{m}\left\|x_{m}\right\|^{2}-\sum_{i \neq j} a_{i} a_{j}\left\|x_{i}-x_{j}\right\|^{2}
$$

$a_{i}, a_{j} \in[0,1]$ with $\sum_{m=1}^{N} a_{m}=1$.

For solving the equilibrium problem, let us assume the following conditions for a bifunction $\phi$ (see [1]):

1) $\phi(x, x)=0$, for all $x \in C$.

2) $\phi(x, y)+\phi(y, x) \leq 0$, for all $x, y \in C$.

3) For each $x, y, z \in C$,

$$
\limsup _{t \rightarrow 0^{+}} \phi(t z+(1-t) x, y) \leq \phi(x, y) .
$$

4) $\phi(x,$.$) is convex and lower semicontinuous for each x \in C$.

Lemma 2.5 (see [1]) Let $C$ be a nonempty closed convex subset of $H$ and let $\phi$ be a bifunction of $C \times C$ into $\mathbb{R}$ satisfying (A1)-(A4). Let $r>0$ and $x \in H$. Then, there exists $z \in C$ such that

$$
\phi(z, y)+\frac{1}{r}\langle y-z, z-x\rangle \geq 0, \quad \forall y \in C .
$$

Lemma 2.6 Let $\phi: C \rightarrow C$ satisfies (A1)-(A4). For $r>0$ and $x \in H$, define a mapping $T_{r}: H \rightarrow C$ as follows:

$$
T_{r} x=\left\{z \in C: \phi(z, y)+\frac{1}{r}\langle y-z, z-x\rangle \geq 0, \forall y \in C\right\} .
$$

Then, the following holds:

1) $T_{r}$ is single valued;

2) $T_{r}$ is firmly nonexpansive, i.e., for any $x, y \in H,\left\|T_{r} x-T_{r} y\right\|^{2} \leq\left\langle T_{r} x-T_{r} y, x-y\right\rangle$;

3) $F\left(T_{r}\right)=E P(\phi)$;

4) $E P(\phi)$ is closed and convex.

In 2013, Mohammad, E. introduce a new hybrid iterative process for finding a common element of the set of common fixed points of a finite family of nonexpansive semigroups and the set of solutions of an equilibrium problem in the framework of Hilbert spaces. He then prove strong convergence of the proposed iterative process. In this paper, we improve Mohammad's result, and obtain follwing main results. 
Mohammad's Theorem 3.1 (see [20]) about nonexpansive semigroups is the special case of our results. Our results improve chang's result in [21].

\section{Main Results}

First, we show the following theorem to our main results.

Theorem 3.1 Let $C$ be nonempty closed convex subset of $H . T(s)(s \geq 0)$ be an uniformly asymptotically nonexpansive semigroups with nonnegative real sequences $\left\{k_{n}\right\}$ with $\left\{k_{n}\right\} \subset\left[1, \infty\right.$ ) and $k_{n} \rightarrow 0$ (as $n \rightarrow \infty)$, then $F(\mathbb{T})$ is a closed and convex subset of $C$.

Proof. Let $\left\{x_{n}\right\}$ be a sequence in $F(\mathbb{T})$, such that $x_{n} \rightarrow x^{*}$. Since $T(s)(s \geq 0)$ be an uniformly asymptotically nonexpansive semigroups, we have

$$
\left\|x_{n}-z\right\|=\left\|T(s) x_{n}-T(s) x^{*}\right\| \leq k_{1}\left\|x_{n}-x^{*}\right\|
$$

for $z=T(s) x^{*}$ and for all $n \in \mathbb{N}$. Therefore,

$$
\left\|x^{*}-z\right\|=\lim _{n \rightarrow \infty}\left\|x_{n}-z\right\| \leq \lim _{n \rightarrow \infty} k_{1}\left\|x_{n}-x^{*}\right\|=k_{1}\left\|x^{*}-x^{*}\right\|=0
$$

We obtain $z=x^{*}$. Hence, $T x^{*}=x^{*}$. So, we have $x^{*} \in F(\mathbb{T})$. This implies $F(\mathbb{T})$ is closed.

Let $p, q \in F(\mathbb{T})$ and $t \in(0,1)$, and put $w=t p+(1-t) q$. Next we prove that $w \in F(\mathbb{T})$. Indeed, in view of Lemma 2.32 ), let $z_{n}=T^{n}(s) w$, we have

$$
\begin{aligned}
\left\|w-z_{n}\right\|^{2} & =\|w\|^{2}-2\left\langle w, z_{n}\right\rangle+\left\|z_{n}\right\|^{2} \\
& =\|w\|^{2}-2\left\langle t p+(1-t) q, z_{n}\right\rangle+\left\|z_{n}\right\|^{2} \\
& =\|w\|^{2}+t\left\|p-z_{n}\right\|+(1-t)\left\|q-z_{n}\right\|-t\|p\|^{2}-(1-t)\|q\|^{2} .
\end{aligned}
$$

Since

$$
\begin{aligned}
& t\left\|p-z_{n}\right\|+(1-t)\left\|q, z_{n}\right\| \\
& \leq t\left(k_{n}-1\right)\|p-w\|+(1-t)\left(k_{n}-1\right)\|q-w\| \\
& =t\left\{\|p\|^{2}-2\langle p, w\rangle+\|w\|^{2}+\left(k_{n}-1\right)\|q-w\|\right\} \\
& \quad+(1-t)\left\{\|q\|^{2}-2\langle q, w\rangle+\|q\|^{2}+\left(k_{n}-1\right)\|q-w\|\right\} \\
& =t\|p\|^{2}+(1-t)\|q\|^{2}-\|w\|^{2}+t\left(k_{n}-1\right)\|p-w\|+(1-t)\left(k_{n}-1\right)\|q-w\| .
\end{aligned}
$$

Substituting (1) into (2) and simplifying it we have

$$
\left\|w-z_{n}\right\| \leq t\left(k_{n}-1\right)\|p-w\|+(1-t)\left(k_{n}-1\right)\|q-w\| \rightarrow 0, \quad(\text { as } n \rightarrow \infty)
$$

Hence, we have $z_{n} \rightarrow w$. This implies that $z_{n+1}=T T^{n} w \rightarrow w$. Since $T(s)$ is closed, we have $T(s) w=w$, i.e., $w \in F(\mathbb{T})$. This completes the proof of theorem 3.1.

Theorem 3.2 Let $C$ be a nonempty closed convex subset of a real Hilbert space $H$ and $\phi$ be $a$ bifunction of $C \times C$ into $\mathbb{R}$ satisfying (A1)-(A4). Let $\mathbb{T}_{i}:=\left\{T_{i}(s): s \geq 0\right\} \quad(i=1,2, \cdots, m)$ be a finite family of uniformly asymptotically semigroups with sequence $\left\{k_{n}^{(i)}\right\}\left(k_{n}^{(i)} \geq 1\right.$ and $\left.\lim _{n \rightarrow \infty} k_{n}^{(i)}=1\right)$. Assume that $\mathbb{F}:=\bigcap_{i=1}^{m} F\left(\mathbb{T}_{i}\right) \cap E P(\phi) \neq \varnothing$. For an initial piont $x_{0} \in C_{0}=C$, let $\left\{x_{n}\right\}$ and $\left\{z_{n}\right\}$ be sequences generated by

$$
\left\{\begin{array}{l}
\phi\left(z_{n}, y\right)+\frac{1}{r_{n}}\left\langle y-z_{n}, z_{n}-x\right\rangle \geq 0, \quad \forall y \in C \\
y_{n}=a_{n, 0} z_{n}+a_{n, 1} T_{1}^{n}\left(t_{n}\right) z_{n}+a_{n, 2} T_{2}^{n}\left(t_{n}\right) z_{n}+\cdots+a_{n, m} T_{m}^{n}\left(t_{n}\right) z_{n} \\
C_{n+1}=\left\{u \in C_{n}:\left\|y_{n}-u\right\| \leq k_{n}\left\|x_{n}-u\right\|\right\} \\
x_{n+1}=P_{C_{n+1}} x_{0}(n=0,1,2, \cdots)
\end{array}\right.
$$

where $P_{D_{n+1}}$ is the metric projection of $H$ onto $D_{n+1}$. If $\left\{a_{n, i}\right\}_{i=0}^{m},\left\{r_{n}\right\},\left\{k_{n}\right\}$ and $\left\{t_{n}\right\}$ satisfying the fol- 
lowing conditions:

1) $k_{n}=\max _{1 \leq i \leq m}\left\{k_{n}^{(i)}, 1\right\}$;

2) $a_{n, i} \in[a, 1)$ (for $i=0,1, \cdots, m$ ) and $\sum_{i=0}^{m} a_{n, i}=1$;

3) $r_{n} \geq 0$ and $\liminf _{n \rightarrow \infty} r_{n}>0$;

4) $\liminf _{n \rightarrow \infty} t_{n}=0, \limsup _{n \rightarrow \infty} t_{n}>0$,

then, the sequences $\left\{x_{n}\right\}$ and $\left\{z_{n}\right\}$ converge strongly to $P_{\mathbb{F}} x_{0}$.

Proof. 1) First, we prove $\mathbb{F}:=\bigcap_{i=1}^{m} F\left(\mathbb{T}_{i}\right) \cap E P(\phi) \subset C_{n}$.

Indeed, $\mathbb{F} \subset C_{0}=C$ is obvious. Suppose that $\mathbb{F} \subset C_{n}$, then for $\forall p \in \mathbb{F}$ and $z_{n}=T_{r_{n}} x_{n}$, by Lemma 2.6 we have

$$
\left\|z_{n}-p\right\|=\left\|T_{r_{n}} x_{n}-T_{r_{n}} p\right\| \leq\left\|x_{n}-p\right\| .
$$
have

Since $\mathbb{T}_{i}:=\left\{T_{i}(s): s \geq 0\right\} \quad(i=1,2, \cdots, m)$ be a finite family of uniformly asymptotically semigroups, we

$$
\begin{aligned}
\left\|y_{n}-p\right\| & =\left\|a_{n, 0} z_{n}+a_{n, 1} T_{1}^{n}\left(t_{n}\right) z_{n}+a_{n, 2} T_{2}^{n}\left(t_{n}\right) z_{n}+\cdots+a_{n, m} T_{m}^{n}\left(t_{n}\right) z_{n}-p\right\| \\
& \leq a_{n, 0}\left\|z_{n}-p\right\|+a_{n, 1}\left\|T_{1}^{n}\left(t_{n}\right) z_{n}-p\right\|+a_{n, 2}\left\|T_{2}^{n}\left(t_{n}\right) z_{n}-p\right\|+\cdots+a_{n, m}\left\|T_{m}^{n}\left(t_{n}\right) z_{n}-p\right\| \\
& \leq a_{n, 0}\left\|z_{n}-p\right\|+a_{n, 1} k_{n}^{(1)}\left\|z_{n}-p\right\|+a_{n, 2} k_{n}^{(2)}\left\|z_{n}-p\right\|+\cdots+a_{n, m} k_{n}^{(m)}\left\|z_{n}-p\right\| \\
& \leq k_{n}\left\|z_{n}-p\right\| \leq k_{n}\left\|x_{n}-p\right\|,
\end{aligned}
$$

which implies that $p \in C_{n+1}$. Therefore we have $\mathbb{F}:=\bigcap_{i=1}^{m} F\left(\mathbb{T}_{i}\right) \cap E P(\phi) \subset C_{n}$ for all $n \geq 0$. Note $C_{n}$ is closed and convex.this implies that $\left\{x_{n}\right\}$ is well defined. From Lemma 2.5, sequence $\left\{z_{n}\right\}$ is also well defined.

2) Next, we prove that $\lim \left\|x_{n}-x_{0}\right\|$ exists.

Since $\mathbb{F}$ is closed and convex subset of $H$, there exists a unique $w \in \mathbb{F}$ such that $w=P_{\mathbb{F}} x_{0}$. From $x_{n}=P_{c_{n}} x_{0} \in c_{n}$, we have

$$
\left\|x_{n}-x_{0}\right\| \leq\left\|x_{n+1}-x_{0}\right\|, \quad n \geq 0 .
$$

Since $w \in \mathbb{F} \subset C_{n}$, we get that

$$
\left\|x_{n}-x_{0}\right\| \leq\left\|w-x_{0}\right\|, \quad n \geq 0 .
$$

It follows that the sequence $\left\{x_{n}\right\}$ is bounded and non decreasing, this implies that $\lim \left\|x_{n}-x_{0}\right\|$ exists 3) Now we show that $\lim _{n \rightarrow \infty} x_{n}=q \in C, \lim _{n \rightarrow \infty}\left\|T_{i}^{n}(s) x_{n}-x_{n}\right\|=0(\forall s \geq 0)$.

Infact, from Lemma 2.2 we have

$$
\left\|x_{m}-x_{n}\right\| \leq\left\|x_{m}-x_{0}\right\|^{2}-\left\|x_{n}-x_{0}\right\|^{2} \rightarrow 0, \text { as } m>n \rightarrow \infty .
$$

witch implies that we get $\left\{x_{n}\right\}$ is Cauchy. Hence there exists $q \in C$ such that $\lim _{n \rightarrow \infty} x_{n}=q \in C$. Since $\left\|y_{n}-x_{n+1}\right\| \leq\left\|x_{n}-x_{n+1}\right\|$, thus $\lim y_{n}=q \in C$. By Lemma 2.4, we have

$$
\begin{aligned}
\left\|y_{n}-p\right\|^{2}= & \left\|a_{n, 0} z_{n}+a_{n, 1} T_{1}^{n}\left(t_{n}\right) z_{n}+a_{n, 2} T_{2}^{n}\left(t_{n}\right) z_{n}+\cdots+a_{n, m} T_{m}^{n}\left(t_{n}\right) z_{n}-p\right\|^{2} \\
\leq & a_{n, 0}\left\|z_{n}-p\right\|^{2}+a_{n, 1}\left\|T_{1}^{n}\left(t_{n}\right) z_{n}-p\right\|^{2}+a_{n, 2}\left\|T_{2}^{n}\left(t_{n}\right) z_{n}-p\right\|^{2} \\
& +\cdots+a_{n, m}\left\|T_{m}^{n}\left(t_{n}\right) z_{n}-p\right\|^{2}-a_{n, 0} a_{n, i}\left\|T_{i}^{n}\left(t_{n}\right) z_{n}-z_{n}\right\|^{2} \\
\leq & a_{n, 0}\left\|z_{n}-p\right\|^{2}+a_{n, 1} k_{n}^{(1)}\left\|z_{n}-p\right\|^{2}+a_{n, 2} k_{n}^{(2)}\left\|z_{n}-p\right\|^{2} \\
& +\cdots+a_{n, m} k_{n}^{(m)}\left\|z_{n}-p\right\|^{2}-a_{n, 0} a_{n, i}\left\|T_{i}^{n}\left(t_{n}\right) z_{n}-z_{n}\right\|^{2} \\
\leq & k_{n}\left\|z_{n}-p\right\|-a_{n, 0} a_{n, i}\left\|T_{i}^{n}\left(t_{n}\right) z_{n}-z_{n}\right\|^{2} \\
\leq & k_{n}\left\|x_{n}-p\right\|^{2}-a_{n, 0} a_{n, i}\left\|T_{i}^{n}\left(t_{n}\right) z_{n}-z_{n}\right\|^{2} .
\end{aligned}
$$


from condition (C1), so we have

$$
a^{2}\left\|T_{i}^{n}\left(t_{n}\right) z_{n}-z_{n}\right\|^{2} \leq a_{n, 0} a_{n, i}\left\|T_{i}^{n}\left(t_{n}\right) z_{n}-z_{n}\right\|^{2} \leq k_{n}\left\|x_{n}-p\right\|^{2}-\left\|y_{n}-p\right\|^{2},
$$

this implies $\lim _{n \rightarrow \infty}\left\|T_{i}^{n}\left(t_{n}\right) z_{n}-z_{n}\right\|=0$ for all $i \geq 1$. We know that $z_{n}=T_{r_{n}} x_{n}$, hence we have

$$
\begin{aligned}
\left\|z_{n}-p\right\|^{2} & =\left\|T_{r_{n}} x_{n}-T_{r_{n}} p\right\|^{2} \leq\left\langle T_{r_{n}} x_{n}-T_{r_{n}} p, x_{n}-p\right\rangle \\
& =\left\langle z_{n}-p, x_{n}-p\right\rangle=\frac{1}{2}\left(\left\|z_{n}-p\right\|^{2}+\left\|x_{n}-p\right\|^{2}-\left\|x_{n}-z_{n}\right\|^{2}\right),
\end{aligned}
$$

that is,

$$
\left\|z_{n}-p\right\|^{2} \leq\left\|x_{n}-p\right\|^{2}-\left\|x_{n}-z_{n}\right\|^{2}
$$

Using (3.5) we get that

$$
\left\|y_{n}-p\right\|^{2} \leq k_{n}\left\|z_{n}-p\right\|^{2} \leq k_{n}\left(\left\|x_{n}-p\right\|^{2}-\left\|x_{n}-z_{n}\right\|^{2}\right)
$$

that is,

$$
\left\|x_{n}-z_{n}\right\|^{2} \leq\left\|x_{n}-p\right\|^{2}-\frac{1}{k_{n}}\left\|y_{n}-p\right\|^{2},
$$

which implies $\lim _{n \rightarrow \infty}\left\|x_{n}-z_{n}\right\|=0$. Hence for all $i \geq 1$ we get that

$$
\begin{aligned}
\left\|T_{i}^{n}\left(t_{n}\right) x_{n}-x_{n}\right\| & \leq\left\|x_{n}-z_{n}\right\|+\left\|T_{i}^{n}\left(t_{n}\right) z_{n}-z_{n}\right\|+\left\|T_{i}^{n}\left(t_{n}\right) z_{n}-T_{i}^{n}\left(t_{n}\right) x_{n}\right\| \\
& \leq\left(1+k_{n}^{(i)}\right)\left\|x_{n}-z_{n}\right\|+\left\|T_{i}^{n}\left(t_{n}\right) z_{n}-z_{n}\right\| \rightarrow 0 \text { as } n \rightarrow \infty .
\end{aligned}
$$

Without loss of generality, as in Saejung's article [17], let $\lim _{n \rightarrow \infty} t_{n}=\lim _{n \rightarrow \infty} \frac{\left\|T_{i}^{n}\left(t_{n}\right) x_{n}-x_{n}\right\|}{t_{n}}=0$. For $s>0$ and $1 \leq i \leq m$,

$$
\begin{aligned}
\left\|T_{i}^{n}(s) x_{n}-x_{n}\right\| & \leq \sum_{k=0}^{\left[\frac{s}{t_{n}}\right]-1}\left\|T_{i}^{n}\left((k+1) t_{n}\right) x_{n}-T_{i}^{n}\left(k t_{n}\right) x_{n}\right\|+\left\|T_{i}^{n}\left(\left[\frac{s}{t_{n}}\right] t_{n}\right) x_{n}-T_{i}^{n}(s) x_{n}\right\| \\
& \leq\left[\frac{s}{t_{n}}\right] k_{n}^{(i)}\left\|T_{i}^{n}\left(t_{n}\right) x_{n}-x_{n}\right\|+\left\|T_{i}^{n}\left(s-\left[\frac{s}{t_{n}}\right] t_{n}\right) x_{n}-T_{i}^{n}(s) x_{n}\right\| \\
& \leq \frac{s}{t_{n}} k_{n}^{(i)}\left\|T_{i}^{n}\left(t_{n}\right) x_{n}-x_{n}\right\|+k_{n} \max \left\{\left\|T_{i}^{n}(t) x_{n}-x_{n}\right\|\right\}, \quad 0<t \leq t_{n},
\end{aligned}
$$

where $[x]$ denotes the maximal integer that is not larger than $x$. Since for $\forall n \geq 0$ mapping $s \rightarrow T_{i}^{n}(s) x$ for a fixed $x \in C$ and $\lim _{n \rightarrow \infty}\left\|T_{i}^{n}\left(t_{n}\right) x_{n}-x_{n}\right\|=0$, then $\lim _{n \rightarrow \infty}\left\|T_{i}^{n}(s) x_{n}-x_{n}\right\|=0(\forall s \geq 0)$.

4) Now we prove that $q \in \mathbb{F}:=\bigcap_{i=1}^{m} F\left(\mathbb{T}_{i}\right) \cap E P(\phi)$.

First, since $z_{n}=T_{r_{n}} x_{n}$ and $\lim _{n \rightarrow \infty}\left\|x_{n}-z_{n}\right\|=0$, by (A2) we get that

$$
\frac{1}{r_{n}}\left\langle y-z_{n}, z_{n}-x_{n}\right\rangle \geq \phi\left(y, z_{n}\right) \quad \forall y \in C
$$

and hence

$$
\left\langle y-z_{n}, \frac{1}{r_{n}}\left(z_{n}-x_{n}\right)\right\rangle \geq \phi\left(y, z_{n}\right) \quad \forall y \in C
$$


Since $\lim _{n \rightarrow \infty} \frac{1}{r_{n}}\left(z_{n}-x_{n}\right)=0, \lim _{n \rightarrow \infty} z_{n}=q$ and $A(4)$, we get that

$$
\phi(y, q) \leq 0 \quad \forall y \in C .
$$

If $t \in(0,1)$ and $y \in C$, let $y_{t}:=t y+(1-t) q$, then $y_{t} \in C$. So, from (A1)-(A4) we have

$$
0=\phi\left(y_{t}, y_{t}\right)=\phi\left(y_{t}, t y+(1-t) q\right) \leq t \phi\left(y_{t}, y\right)+(1-t) \phi\left(y_{t}, q\right) \leq t \phi\left(y_{t}, y\right)
$$

which gives $\phi\left(y_{t}, y\right) \geq 0$ for all $y \in C$. Hence by (A3) we have

$$
0 \leq \limsup _{t \rightarrow 0^{+}} \phi\left(y_{t}, q\right) \limsup _{t \rightarrow 0^{+}} \phi(t y+(1-t) q, y) \leq \phi(q, y) \quad \forall y \in C,
$$

which is $q \in E P(\phi)$.

For $i=1,2, \cdots, m$, we have

$$
\begin{aligned}
\left\|q-T_{i}(s) q\right\| & \leq\left\|q-x_{n}\right\|+\left\|x_{n}-T_{i}^{n}(s) x_{n}\right\|+\left\|T_{i}^{n}(s) x_{n}-T_{i}(s) q\right\| \\
& \leq\left\|q-x_{n}\right\|+\left\|x_{n}-T_{i}^{n}(s) x_{n}\right\|+k_{n}^{(i)}\left\|T_{i}^{n-1}(s) x_{n}-q\right\| \\
& \leq\left\|q-x_{n}\right\|+\left\|x_{n}-T_{i}^{n}(s) x_{n}\right\|+k_{n}^{(i)}\left(\left\|T_{i}^{n-1}(s) x_{n}-T_{i}^{n-1}(s) x_{n-1}\right\|+\left\|T_{i}^{n-1}(s) x_{n-1}-q\right\|\right) \\
& \leq\left\|q-x_{n}\right\|+\left\|x_{n}-T_{i}^{n}(s) x_{n}\right\|+k_{n}^{(i)} k_{n-1}^{(i)}\left(\left\|x_{n}-x_{n-1}\right\|+\left\|T_{i}^{n-1}(s) x_{n-1}-q\right\|\right)
\end{aligned}
$$

Since $\lim _{n \rightarrow \infty}\left\|T_{i}^{n-1}(s) x_{n-1}-q\right\|=0$, then $T_{i}(s) q=q$ i.e., $q \in F\left(\mathbb{T}_{i}\right)$ for all $i=1,2, \cdots, m$ and thus $q \in \mathbb{F}:=\bigcap_{i=1}^{m} F\left(\mathbb{T}_{i}\right) \cap E P(\phi)$.

5) Now we prove that $q=P_{\mathbb{F}} x_{0}$.

Since $x_{n}=P_{C_{n}} x_{0} \in C_{n}$ and $\mathbb{F} \subset C_{n}$, we get that

$$
\left\|x_{n}-x_{0}\right\| \leq\left\|p-x_{0}\right\| \quad p \in \mathbb{F} \quad \forall n \geq 0 .
$$

Since $\lim _{n \rightarrow \infty} x_{n}=q$, we have

$$
\left\|q-x_{0}\right\| \leq\left\|p-x_{0}\right\| \quad p \in \mathbb{F} \quad \forall n \geq 0,
$$

which implies $q=P_{\mathbb{F}} x_{0}$. The proof is completed.

From Theorem 3.1, taking $\phi \equiv 0$ and $r_{n}=1$, we obtain

Corollary 3.1 Let $C$ be a nonempty closed convex subset of a real Hilbert space $H$ and $\phi$ be $a$ bifunction of $C \times C$ into $\mathbb{R}$ satisfying (A1)-(A4). Let $\mathbb{T}_{i}:=\left\{T_{i}(s): s \geq 0\right\} \quad(i=1,2, \cdots, m)$ be a finite family of uniformly asymptotically semigroups with sequence $\left\{k_{n}^{(i)}\right\}\left(k_{n}^{(i)} \geq 1\right.$ and $\left.\lim _{n \rightarrow \infty} k_{n}^{(i)}=1\right)$. Assume that $\mathbb{F}:=\bigcap_{i=1}^{m} F\left(\mathbb{T}_{i}\right) \cap E P(\phi) \neq \varnothing$. For an initial piont $x_{0} \in C_{0}=C$, let $\left\{x_{n}\right\}$ and $\left\{z_{n}\right\}$ be sequences generated by

$$
\left\{\begin{array}{l}
y_{n}=a_{n, 0} x_{n}+a_{n, 1} T_{1}^{n}\left(t_{n}\right) x_{n}+a_{n, 2} T_{2}^{n}\left(t_{n}\right) x_{n}+\cdots+a_{n, m} T_{m}^{n}\left(t_{n}\right) x_{n} \\
C_{n+1}=\left\{u \in C_{n}:\left\|y_{n}-u\right\| \leq k_{n}\left\|x_{n}-u\right\|\right\} \\
x_{n+1}=P_{C_{n+1}} x_{0} \quad(n=0,1,2, \cdots)
\end{array}\right.
$$

where $P_{D_{n+1}}$ is the metric projection of $H$ onto $D_{n+1}$. If $\left\{a_{n, i}\right\}_{i=0}^{m},\left\{r_{n}\right\},\left\{k_{n}\right\}$ and $\left\{t_{n}\right\}$ satisfying the following conditions:

1) $k_{n}=\max _{1 \leq i \leq m}\left\{k_{n}^{(i)}, 1\right\}$;

2) $a_{n, i} \in[a, 1)$ (for $i=0,1, \cdots, m$ ) and $\sum_{i=0}^{m} a_{n, i}=1$;

3) $\liminf _{n \rightarrow \infty} t_{n}=0, \limsup _{n \rightarrow \infty} t_{n}>0$, then, the sequences $\left\{x_{n}\right\}$ converge strongly to $P_{\mathbb{F}} x_{0}$.

\section{Competing Interests}

The authors declare that they have no competing interests. 


\section{Acknowledgements}

The authors are very grateful to reviewers for carefully reading this paper and their comments. This work is supported by the Doctoral Program Research Foundation of Southwest University of Science and Technology (No. 11zx7129) and Applied Basic Research Project of Sichuan Province (No. 2013JY0096).

\section{References}

[1] Blum, E. and Oettli, W. (1994) From Optimization and Variational Inequalities to Equilibrium Problems. Mathematics Students, 63, 123-145.

[2] Flam, S.D. and Antipin, A.S. (1997) Equilibrium Programming Using Proximal-Link Algolithms. Mathematical Programming, 78, 29-41. http://dx.doi.org/10.1007/BF02614504

[3] Moudafi, A. and Thera, M. (1999) Proximal and Dynamical Approaches to Equilibrium Problems. Lecture Note in Economics and Mathematical Systems, 477, 187-201.

[4] Bauschke, H.H. and Borwein, J.M. (1996) On Projection Algorithms for Solving Convex Feasibility Problems. SIAM Review, 38, 367-426. http://dx.doi.org/10.1137/S0036144593251710

[5] Butnariu, D., Censor, Y., Gurfil, P. and Hadar, E. (2008) On the Behavior of Subgradient Projections Methods for Convex Feasibility Problems in Euclidean Spaces. SIAM Journal on Optimization, 19, 786-807. http://dx.doi.org/10.1137/070689127

[6] Hale, E.T., Yin, W. and Zhang, Y. (2010) Fixed-Point Continuation Applied to Compressed Sensing: Implementation and Numerical Experiments. Journal of Computational Mathematics, 28, 170-194.

[7] Maruster, S. and Popirlan, C. (2008) On the Mann-Type Iteration and the Convex Feasibility Problem. Journal of Computational and Applied Mathematics, 212, 390-396. http://dx.doi.org/10.1016/j.cam.2006.12.012

[8] Byrne, C. (2004) A Unified Treatment of Some Iterative Algorithms in Signal Processing and Image Reconstruction. Inverse Problems, 20, 103-120. http://dx.doi.org/10.1088/0266-5611/20/1/006

[9] Censor, Y., Elfving, T., Kopf, N. and Bortfeld, T. (2005) The Multiple-Sets Split Feasibility Problem and Its Applications for Inverse Problems. Inverse Problems, 21, 2071-2084. http://dx.doi.org/10.1088/0266-5611/21/6/017

[10] Xu, H.K. (2006) A variable Krasnoselskii-Mann Algorithm and Themultiple-Set Split Feasibility Problem. Inverse Problems, 22, 2021-2034. http://dx.doi.org/10.1088/0266-5611/22/6/007

[11] Mann, W.R. (1953) Mean Value Methods in Iteration. Proceedings of the American Mathematical Society, 4, 506-510. http://dx.doi.org/10.1090/S0002-9939-1953-0054846-3

[12] Nakajo, K. and Takahashi, W. (2003) Strong Convergence Theorems for Nonexpansive Mappings and Nonexpansive Semigroups. Journal of Mathematical Analysis and Applications, 279, 372-379. http://dx.doi.org/10.1016/S0022-247X(02)00458-4

[13] Takahashi, W., Takeuchi, Y. and Kubota, R. (2008) Strong Convergence Theorems by Hybrid Methods for Families of Nonexpansive Mappings in Hilbert Spaces. Journal of Mathematical Analysis and Applications, 341, 276-286. http://dx.doi.org/10.1016/j.jmaa.2007.09.062

[14] Suzuki, T. (2003) On Strong Convergence to Common Fixed Points of Nonexpansive Semigroups in Hilbert Spaces. Proceedings of the American Mathematical Society, 131, 2133-2136. http://dx.doi.org/10.1090/S0002-9939-02-06844-2

[15] Tada, A. and Takahashi, W. (2007) Weak and Strong Convergence Theorems for a Nonexpansive Mapping and an Equilibrium Problem. Journal of Optimization Theory and Applications, 133, 359-370. http://dx.doi.org/10.1007/s10957-007-9187-z

[16] He, H. and Chen, R. (2007) Strong Convergence Theorems of the CQ Method for Nonexpansive Semigroups. Fixed Point Theory and Applications, 2007, Article ID 59735.

[17] Saejung, S. (2008) strong Convergence Theorems for Nonexpansive Semigroups without Bochner Integrals. Fixed Point Theory and Applications, 2008, Article ID 745010.

[18] Marino, G. and Xu, H.K. (2007) Weak and Strong Convergence Theorems for Strict Pseudo-Contractions in Hilbert Space. Journal of Mathematical Analysis and Applications, 329, 336-346. http://dx.doi.org/10.1016/j.jmaa.2006.06.055

[19] Cholamjiak, W. and Suantai, S. (2010) Ahybrid Method for a Countable Family of Multivalued Maps, Equilibrium Problems, and Variational Inequality Problems. Discrete Dynamics in Nature and Society, 2010, Article ID: 349158.

[20] Mohammad, E. (2013) Hybid Method for Equilibrium Problems and Fixed Piont Problems of Finite of Nonexpansive Semigroups. Revista Serie A Matemáticas, 107, 299-307. 
[21] Chang, S.S., Wang, L., Tang, Y.K., Wang, B. and Qin, L.J. (2012) Strong Convergence Theorems for a Countable Family of Quasi- $\varphi$-Asymptotically Nonexpansive Nonself Mappings. Applied Mathematics and Computation, 218, 78647870. http://dx.doi.org/10.1016/j.amc.2012.02.002 